\title{
La apuesta por la integración de contenidos de Ebsco
}

\section{Por Jose A. Senso y Mari Carmen Marcos}

Ebsco Information Services lleva más de 60 años proporcionando servicios de suscripción a la comunidad bibliotecaria. A su labor tradicional de agente de suscripciones, Ebsco ha ido sumando servicios y productos para cubrir las nuevas necesidades de las bibliotecas e instituciones en el mundo de la información electrónica.

Con la aparición de la revista electrónica en los años 90, la empresa norteamericana creó su primer portal de acceso a revistas electrónicas, Ebsco Online. Dicho portal se convirtió en el año 2002 en EBSCOhost Electronic Journals Service (EJS), un sistema de gestión y acceso a suscripciones electrónicas adaptado a la nueva complejidad y cantidad de recursos disponibles. Con el incremento de recursos electrónicos suscritos por las bibliotecas nació la Lista $A-Z$ (A-to-Z), servicio que proporciona un listado de todos los recursos electrónicos disponibles en una lista en formato web totalmente personalizable. El portal de bases de datos EBSCOhost cuenta con más de 150 bases de datos, referenciales y con texto completo. El servidor de enlaces OpenURL LinkSource completa la oferta de servicios para la gestión y acceso a recursos electrónicos de Ebsco. Todos estos servicios utilizan la tecnología de enlaces SmartLinks, que hace que la integración de acceso a los distintos recursos sea transparente para el usuario. Por su parte, EJS da acceso a las publicaciones electrónicas suscritas por medio de Ebsco así como a los su- 


\section{LinkSource}

Las actuales colecciones electrónicas incluyen gran cantidad de información en diferentes formatos y con múltiples formas de acceso: revistas electrónicas, bases de datos a texto completo o referenciales, opacs... La mayoría de estos sistemas emplean tecnologías propietarias para gestionar la información, obligando al usuario a emplear interfaces de búsqueda heterogéneos para localizar artículos de revista sobre una misma temática o los artículos de un autor determinado en diversas publicaciones. La solución propuesta por Ebsco para resolver este problema responde al nombre comercial de LinkSource: sistema que ofrece acceso a todo este tipo de información de manera transparente para el usuario y que se puede integrar en todos los productos de la empresa.

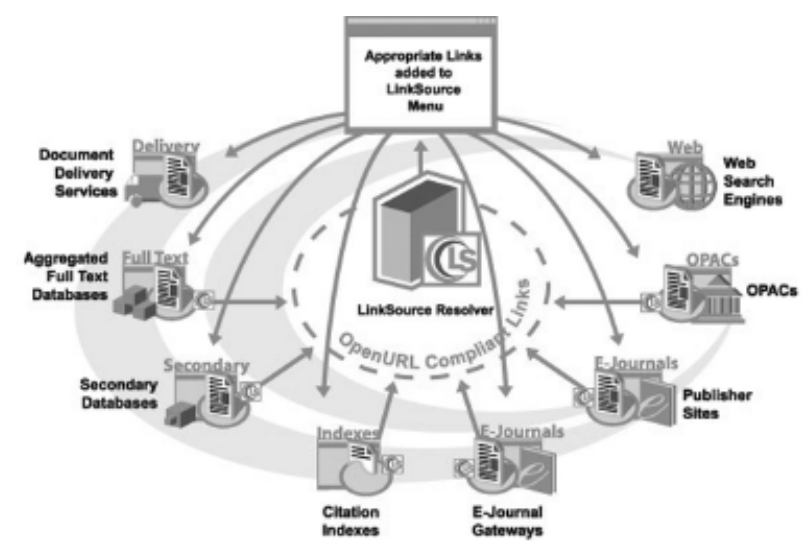

LinkSource es un servidor de enlaces compatible con el estándar Ope$n U R L$ recién aprobado por NISO con la designación Z39.88, que permite la identificación y recuperación de recursos web citados en capítulos de libros y artículos de revistas. Esta norma no es más que una sintaxis que gestiona los metadatos embebidos dentro de enlaces URI de manera controlada. Para ello se generan URLs de forma automática que contienen el DNS del distribuidor, el típo de texto (article, chapter...), el issn o el isbn del documento donde se publicó y el resto de datos identificativos del mismo: para artículos serían volumen, número y página; y para libros sería sólo el isbn y la página de comienzo. Por ejemplo, el OpenURL de este artículo sería:

http://www.metapress.com/openurl.asp?genre=article\&issn $=1386-$ 6710 \&volume $=14$ \&issue $=3$ \&spage $=309$

El servidor OpenURL también se encargaría de gestionar la disponibilidad del texto, las opciones de visualización que tendría el usuario en función del contrato realizado con la distribuidora, etc.

Gracias a esta norma, LinkSource puede añadir enlaces a nivel de artículo en la mayoría de recursos electrónicos del centro sin limitaciones sobre cuál sea el proveedor. El menú de los enlaces se crea dinámicamente utilizando la referencia de cada artículo y obedeciendo a las reglas definidas por la biblioteca.

La gran ventaja que añade Ebsco es la centralización del servicio, ya que no requiere un servidor local. Los técnicos de la empresa americana son los encargados de mantener la actualización del servidor periódicamente, y desde la oficina de EBSCO en España se da apoyo técnico y se configura y personaliza el sistema de acuerdo con las preferencias de la biblioteca

http://www.linkresolver.com marios y resúmenes de publicaciones no suscritas. Se espera la versión en español para el verano de 2005.

\section{Atoz}

Se trata del servicio que ofrece Ebsco para la gestión de publicaciones periódicas distribuidas tanto en paquetes de editores (individuales o colectivos) como por medio de bases de datos. Como gran novedad permite incluir los títulos en formato papel suscritos por la biblioteca. El sistema se articula en torno a un listado general de títulos, organizado de diferentes maneras para garantizar más puntos de acceso, que permite llegar, de manera transparente, a la información en texto completo o referencial, ya esté ubicada en una base de datos, un paquete de revistas o el mismo opac de la institución.

Hay que destacar, como punto fuerte del servicio, que no es necesario que el centro sea cliente de Ebsco, ya que la plataforma está pensada para integrarse con cualquier otro producto comercial que distribuya revistas electrónicas. Aunque es evidente que se obtendrá un mayor rendimiento si se contratan el resto de servicios de Ebsco, como los comentados en este texto.

La principal ventaja de esta plataforma radica en la presentación de una lista personalizada que incluye todos los títulos electrónicos a los que está suscrita la institución. Independientemente del distribuidor, editor o la forma de acceso, todas las publicaciones aparecerán en dicho listado, proporcionando una forma rápida, uniforme y centralizada de organizar una información que, habitualmente, es presentada en la mayoría de bibliotecas distribuida en tantos grupos, bloques, apartados... que hacen que su acceso sea, como mínimo, tedioso. 
Este listado de títulos no es estático, se encuentra en constante evolución. Se añaden, eliminan y actualizan diariamente numerosas publicaciones, evitando así enlaces muertos o tiempos de espera innecesarios. La versión en español de la lista AtoZ estará disponible durante el verano del año 2005. Además, al listado de títulos sucritos por los centros se les suman más de 1.000 revistas electrónicas de acceso libre, que forman parte de proyectos como Directory of Open Access Journals, PubMed Central, Scielo o Free Medical Journals. http://www.doaj.org http://www.pubmedcentral.nih.gov http://www.scielo.org http://www.freemedicaljournals.com/

Una reciente actualización llevada a cabo, AtoZ with marc, suministra un fichero personalizable en formato marc 21 que incluye la descripción de las suscripciones electrónicas de la biblioteca con la url correspondiente a cada título.

El sistema ofrece dos herramientas: la plataforma administrativa y el módulo de usuario. A continuación analizaremos brevemente cada uno de ellos:

Plataforma administrativa. Sistema que, por medio de una interfaz web, permite gestionar de

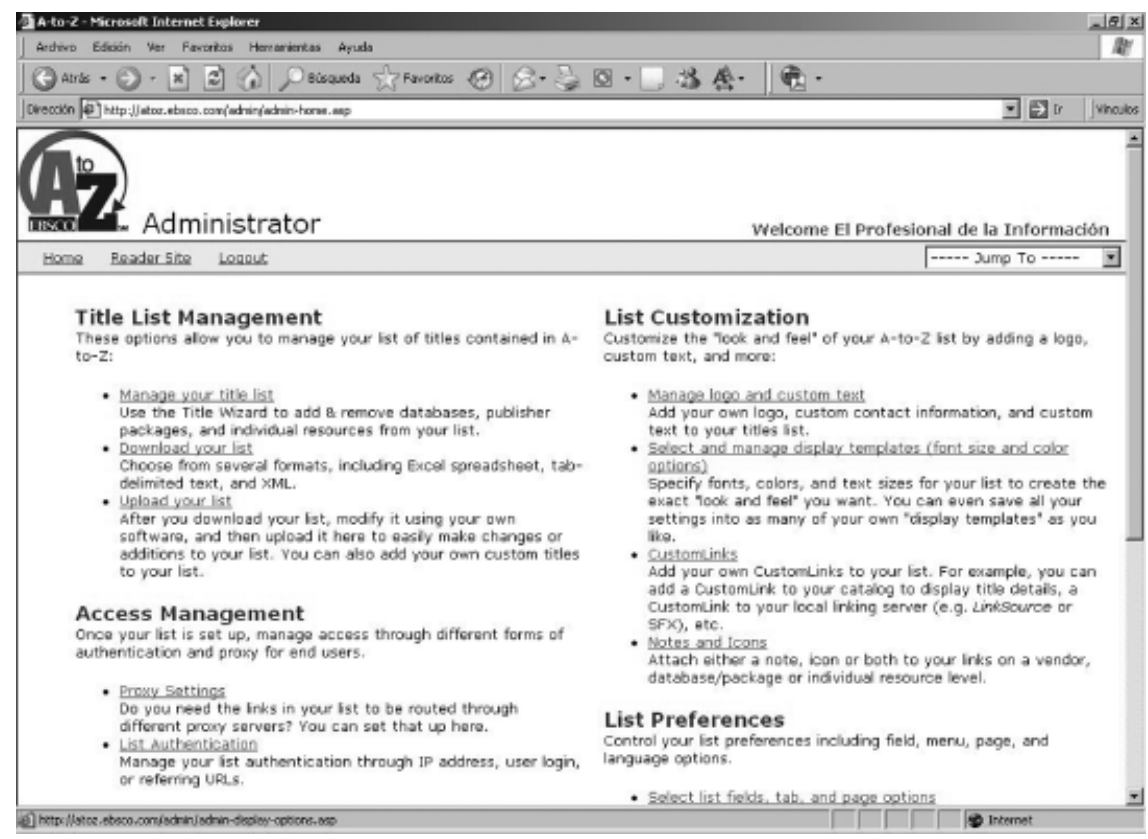

Figura 1. Aspecto de la interfaz de gestión de la plataforma administrativa de AtoZ

forma centralizada la visualización y los títulos electrónicos a los que se está suscrito. La pantalla principal organiza las diferentes opciones agrupándolas en 5 categorías:

- Gestión de títulos (title list management): permite configurar la lista de revistas que aparecerán en el módulo de usuario. La plataforma muestra todas las revistas agrupadas por distribuidores y, en caso de que éstos dispongan de más de un título, es posible acudir a información detallada con los datos de todas ellas. En ocasiones, determinadas revistas no se pueden

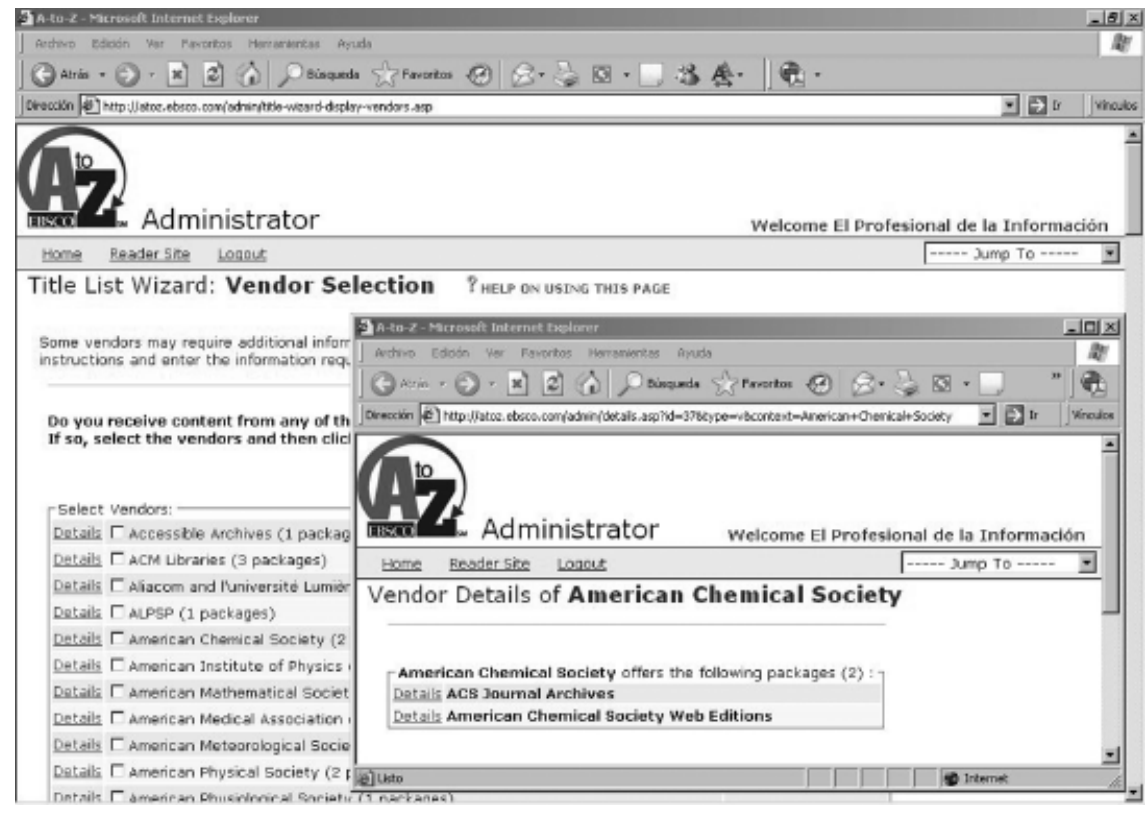

Figura 2. Información detallada sobre el contenido ofrecido por un vendedor determinado adquirir de forma individual, sino que debe hacerse en grupo (denominados "paquetes"). La opción package selection permite añadir al listado de títulos un paquete de revistas o una base de datos a un servicio ya seleccionado. Por último, y para revistas que se distribuyen individualmente, existe un mecanismo para localizarlas, seleccionarlas y añadirlas al listado definitivo.

El listado de todos los títulos con información relativa a la publicación, su URL, issn (tanto de la versión online como de la impresa), la cobertura, palabras clave y período de suscripción se puede descargar en formato $\mathrm{xml}$, delimitado por tabulaciones o Excel. Una vez editado ese fichero en modo local (para, por ejemplo, incluir títulos en formato papel de la biblioteca) se puede volver a subir a la plataforma por medio de un sencillo formulario web.

— Gestión de acceso (access management): el control de acceso a la lista de títulos se realiza de dos maneras diferentes. Por un lado se puede emplear un proxy, que es totalmente configurable desde la consola de administración, y que permite controlar el acceso de una 
máquina cualquiera a los títulos de la colección por medio de su issn o título. El servidor proxy se puede asignar a todos los títulos de un vendedor, los de un páquete o a títulos individuales. El otro método para controlar el acceso a los recursos se realiza por medio de diferentes controles de autentificación: url, ip o rango de ips y gestión de nombres de usuario y contraseñas.

- Informes de utilización (usage reports): genera una serie de estadísticas de uso de la plataforma basándose en diferentes criterios como número de sesiones realizadas, búsquedas efectuadas por los usuarios, linkout (número de veces que un usuario pincha en un vínculo) de recursos, editores, distribuidores, etc. durante determinados periodos de tiempo (días, semanas, meses, años o un rango específico). Todos estos informes se almacena en formato Excel o delimitado por tabulaciones para facilitar su estudio en una hoja de cálculo y/o base de datos.

-Configuración de la lista (list customization y list preferences): con la finalidad de integrar mejor AtoZ dentro del entorno de trabajo, la plataforma permite personalizar las páginas por las que navegará el usuario para añadir el
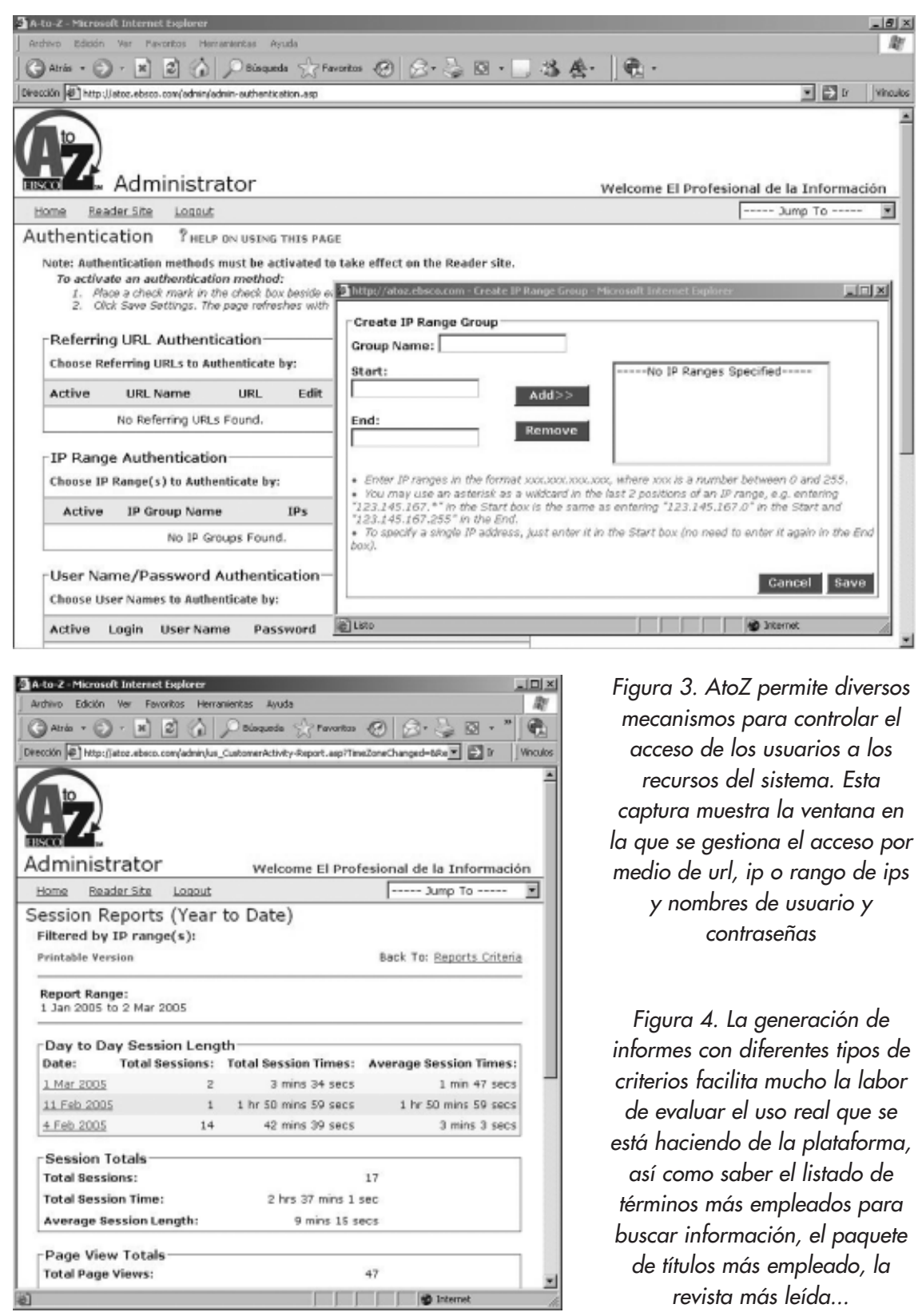

Figura 3. AtoZ permite diversos mecanismos para controlar el acceso de los usuarios a los recursos del sistema. Esta captura muestra la ventana en la que se gestiona el acceso por medio de url, ip o rango de ips y nombres de usuario $y$ contraseñas

Figura 4. La generación de informes con diferentes tipos de criterios facilita mucho la labor de evaluar el uso real que se está haciendo de la plataforma, así como saber el listado de términos más empleados para buscar información, el paquete de títulos más empleado, la revista más leída... logotipo corporativo, mensajes de recordatorio, cambiar el título de cada página, delimitar el número de títulos por página y ordenar la información en función a varios criterios. Las posibilidades de configuración no se limitan sólo a lo estético. De todas las opciones que permiten construir un entorno de trabajo propio destacamos, por ejemplo CustomLinks, que facilita la adición de enlaces tanto al opac como a alguna referencia dentro de éste o a textos de otros distribuidores por medio de LinkSource.

Módulo de usuario. Una vez configurado el entorno, el usuario accederá a una interfaz que presenta la lista de recursos organizados en cuatro pestañas, ubicadas en la parte superior de la pantalla. La primera de ellas lleva al índice, es decir, el listado de todos los distribuidores a los que se está suscrito (que previamente han sido dados de alta en el módulo de administrador) y, entre paréntesis, el acceso al listado completo de sus títulos. La segunda muestra el listado alfabético de los títulos de todos los distribuidores. Inmediatamente debajo de cada título aparecerá el/los distribuidor/es que se encarga/n de ella y el período cronológico que recogen.

Además de estos listados, también se accede a las publicaciones por medio de la pestaña que las agrupa por materias, mostrando la relación jerárquica con un nivel de especificidad que indica el número de títulos dentro de cada rama. Por último, el módulo cuenta con la opción de búsqueda avanzada, que ofrece diversas posibilidades de consulta para localizar los títulos con más facilidad.

Independientemente del sistema escogido para llegar a la publicación que interese, una vez seleccionada ésta se accederá en una ventana nueva del navegador a la plataforma que gestiona dicho título. 


\section{EBSCOhost}

Es la plataforma de base de datos de Ebsco, e incluye las bases de datos referenciales más usadas en las distintas disciplinas académicas, así como bases de datos temáticas de producción propia, a las que incorpora texto completo. Para solventar el problema de acceso a artículos de revistas de distintos grupos editores Ebsco creó el servicio EBSCOhost, banco de información que proporciona una interfaz única de búsqueda para el acceso a títulos de diversos editores y, al mismo tiempo, al documento en texto completo.

El acceso a la página principal del sistema mostrará, dependiendo de cómo se haya configurado con la herramienta EBSCOadmin, el listado de todas las bases de datos, o un listado de "grupos de interés", que no es más que una forma de aglutinar a los usuarios en función de sus necesidades. Si se opta por este último caso lo habitual es agruparlos por temas. También es posible acceder directamente a la página de búsqueda de una base de datos en concreto sin tener que pasar por estas pantallas previas.

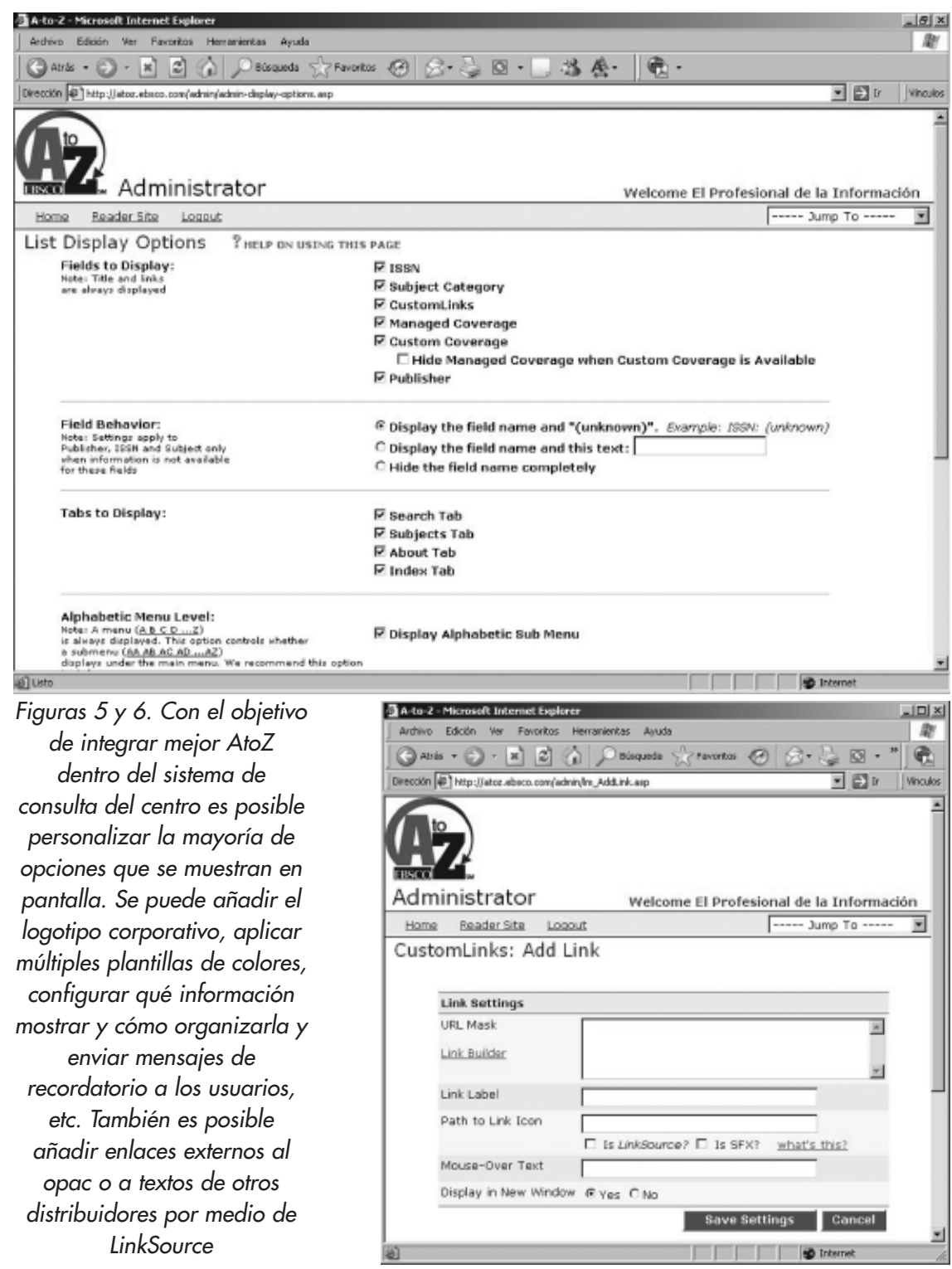

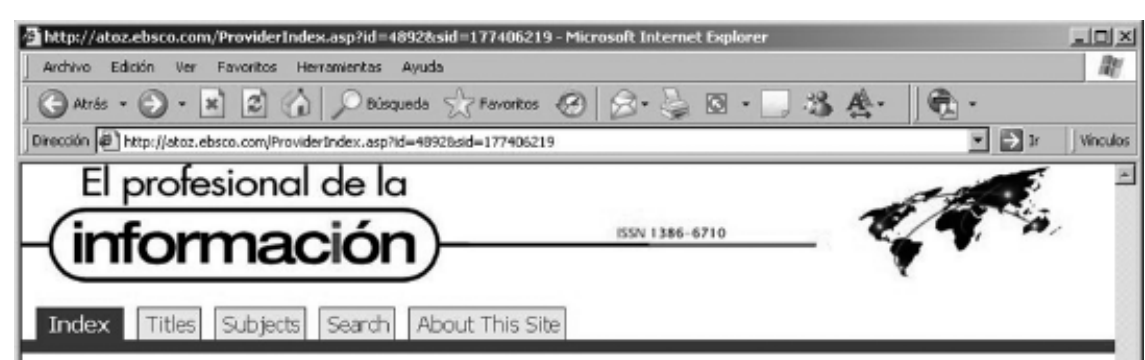
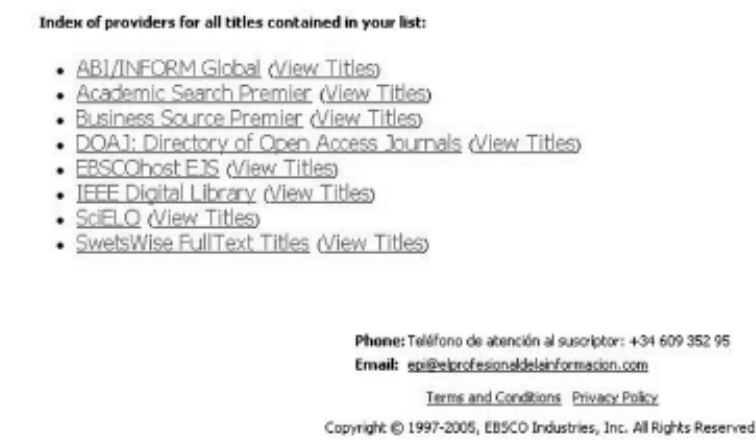

J listo

Figura 7. El módulo de usuario presenta la información agrupada en cuatro pestañas que se muestran en la parte superior de la pantalla. La navegación se realizará en función de las opciones escogidas por el administrador en la configuración de las listas
La página con el listado de las bases de datos muestra, debajo del título que las reúne, un breve resumen de qué es lo que podemos esperar de ella en función de la temática, el número total de títulos, los formatos de salida y la actualización. También es posible obtener un listado concreto de los títulos que conforman dicha base de datos así como una descripción muy detallada sobre tipos de consulta, campos por los que se puede consultar, sistema de búsqueda por browsing, tesauro, derechos de autor y restricciones de uso. La descripción completa de todas las bases de datos se encuentra en: http://www.epnet.com

Una vez seleccionadas las bases de datos con las que trabajar se 
entra directamente al formulario de búsqueda. Dependiendo de cómo se haya configurado previamente el sistema, la consulta será la simple o la avanzada. En la simple la búsqueda se realizará sobre el índice básico pero, por si fuera necesario, existe la posibilidad de emplear limitadores. Dado que cada base de datos puede tener limitadores diferentes, EBSCOhost los ordena por base de datos, de tal forma que debajo del nombre de cada una de ellas encontraremos la opción de especificar fechas, consulta sólo en publicaciones con referees, número de páginas, idioma, género, resumen, número ERIC... dependiendo de lo contemplado en cada una de las fuentes escogidas. Además, el usuario cuenta con "ampliadores", que es el nombre dado por Ebsco a las opciones para preguntar por palabras relacionadas

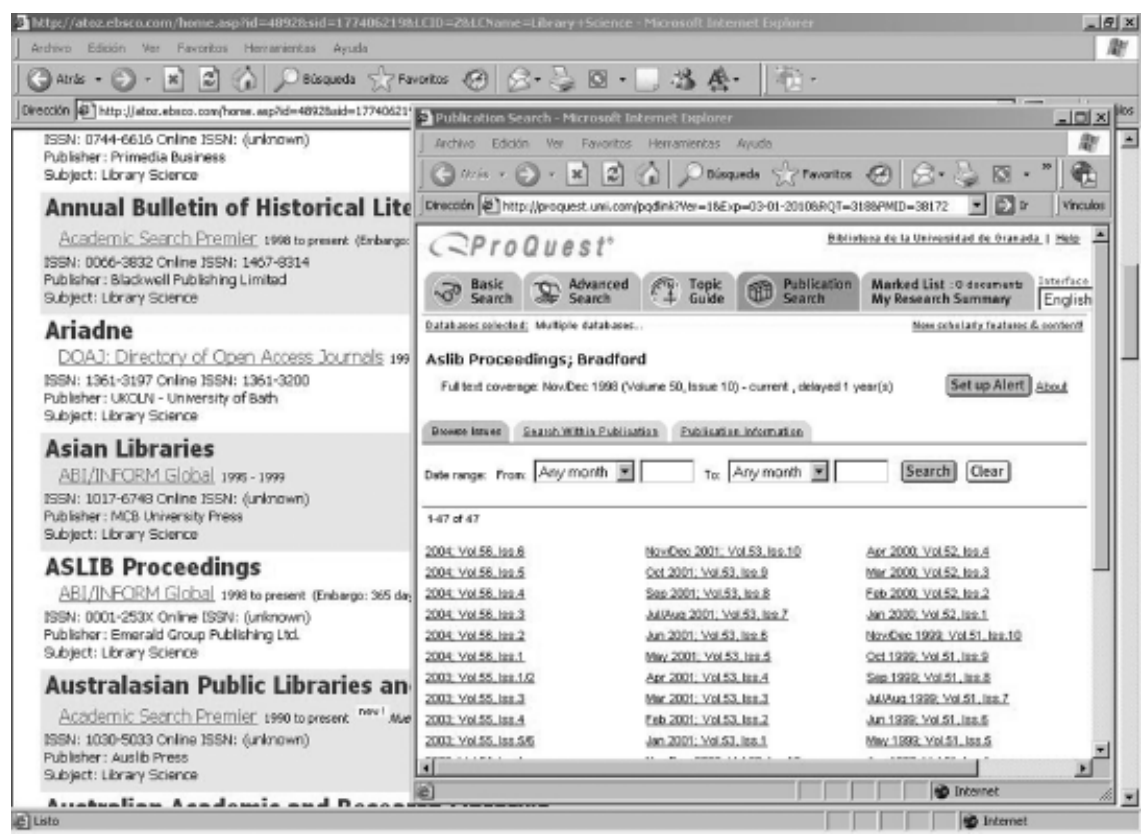

Figura 8. Una vez escogida la publicación en concreto, AtoZ lanza una nueva ventana en el navegador con el acceso directo al título que nos interesa en el web del distribuidor correspondiente

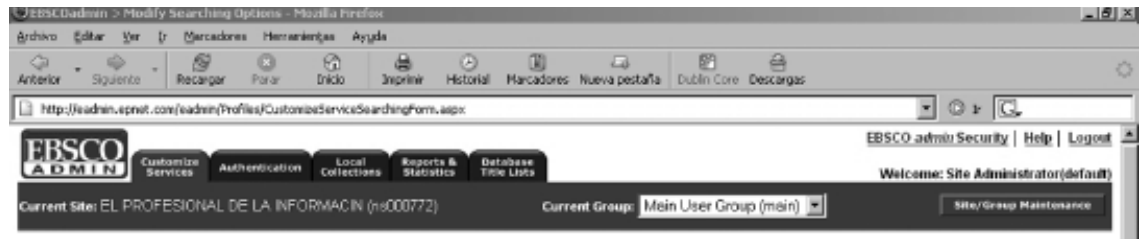

Customize EBSCO services

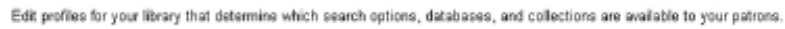

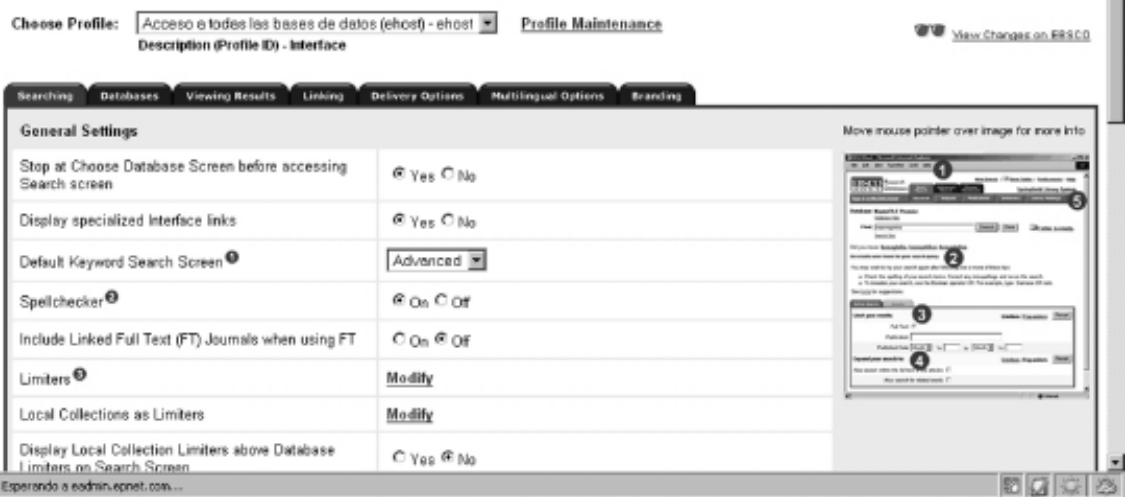

Figura 9. EBSCOadmin es la plataforma remota que se emplea para gestionar tanto el acceso como la interfaz de EBSCOhost. El control que se realiza del sistema de bases de datos es total, permitiendo administrar los títulos ofrecidos, las opciones de consulta, el control por ip o contraseña, la formación de grupos de usuarios para ofrecerles bases de datos específicas a sus necesidades, la generación de informes y estadísticas de uso... (parecido al clásico expand), buscar también en el texto completo del artículo o hacer automáticamente una búsqueda con el operador Y.

La búsqueda avanzada, por su parte, faculta a realizar la consulta por campos determinados y a acceder a un mayor número de limitadores (especificar el tipo de publicación, tipo de documento, artículo con imágenes, nivel educativo, disponibilidad, subconjunto de publicación, etc.) que están organizados de la forma antes comentada para la interfaz simple.

Los resultados de las consultas se pueden ordenar por fecha (por defecto), fuente o relevancia. En cualquiera de las tres modalidades aparecerán con la referencia bibliográfica completa y con el enlace directo al documento o al opac de la institución con el registro de dicha publicación. En el caso de que la revista no se encuentre en los fondos de la biblioteca, el logotipo de texto completo será sustituido por otro que apunta al sistema de préstamo interbibliotecario.

En la parte de la derecha de cada uno de los registros resultantes aparecerá una pequeña carpeta. Se utiliza para añadir ese registro a $\mathrm{Mi}$ EBSCOhost, un sistema de personalización del sistema para el usuario, con la posibilidad de crear una especie de repositorio que, en función de los artículos que allí se depositen, creará automáticamente alertas de las revistas en las que fueron publicados dichos textos, alertas SDI que respondan a unos criterios de búsqueda determinados, perfiles de usuario e, incluso, páginas web personalizadas con contenidos de EBSCOhost y/o de otras fuentes externas. El histórico de búsquedas, que sólo está disponible en la interfaz avanzada, también permite crear alertas y perfiles de usuario en función de las peticiones realizadas en las diferentes sesiones. 
Por último, el usuario puede configurar la interfaz con la opción de "preferencias". Desde ella podrá decidir el número de resultados por página que mostrará el sistema tras una consulta o la cantidad de información a recibir (título, resumen o detallado). Aunque es EBSCOadmin la herramienta clave para la gestión del entorno.

\section{EBSCOadmin}

Se trata de la plataforma remota que se encarga de gestionar la configuración de EBSCOhost. Las acciones que se pueden realizar se dividen en cinco bloques representados por otras tantas pestañas en la parte superior de la interfaz:

Customize services: da acceso a la mayoría de opciones relativas a la búsqueda, acceso a colecciones y organización de la interfaz de EBSCOhost. Una vez seleccionado el perfil con el que se desea trabajar (es posible crear tantos perfiles como grupos distintos de usuarios existan - biblioteca de ciencias de la salud, de economía, acceso a todos los fondos, etc. - y asociarles las bases de datos que más se ajusten a sus necesidades) el sistema permite configurar:

-Búsqueda: determina qué opciones de consulta se mostrarán al usuario, qué posibilidades ofrecerá la interfaz básica o avanzada, duración de la sesión, envío de alertas, tipo de historial de búsque$\mathrm{da}$, diferentes tipos de ayuda (uso de palabras clave, sugerir palabras, limitadores, expandir consulta, verificador ortográfico...).

- Bases de datos: sirve para especificar qué bases de datos se mostrarán al usuario y en qué orden. Además, desde aquí se puede seleccionar cuál será la primera página que vea el usuario una vez haya seleccionado la base de datos con la que desea trabajar: si será el listado de palabras clave, el tesauro, la lista de empresas en las bases de datos empresariales, la lista

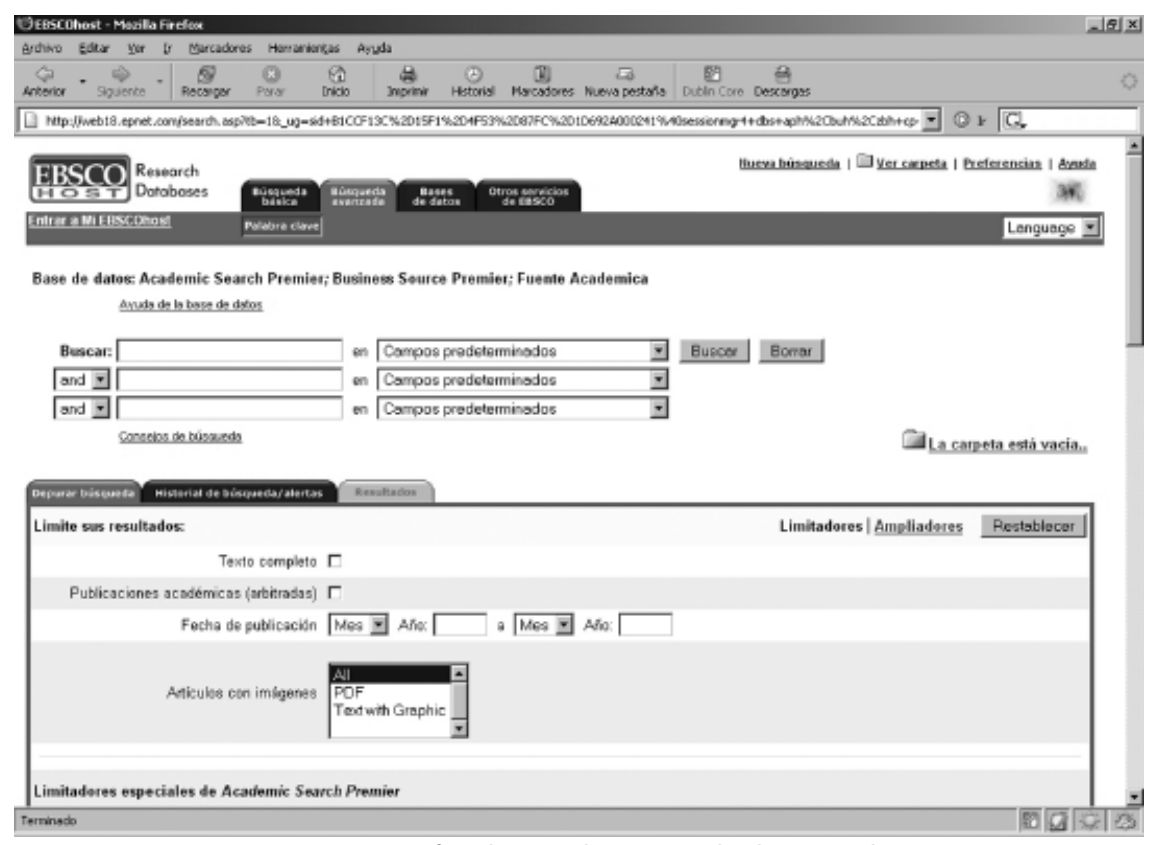

Figura 10. Interfaz de consulta avanzada de EBSCOhost

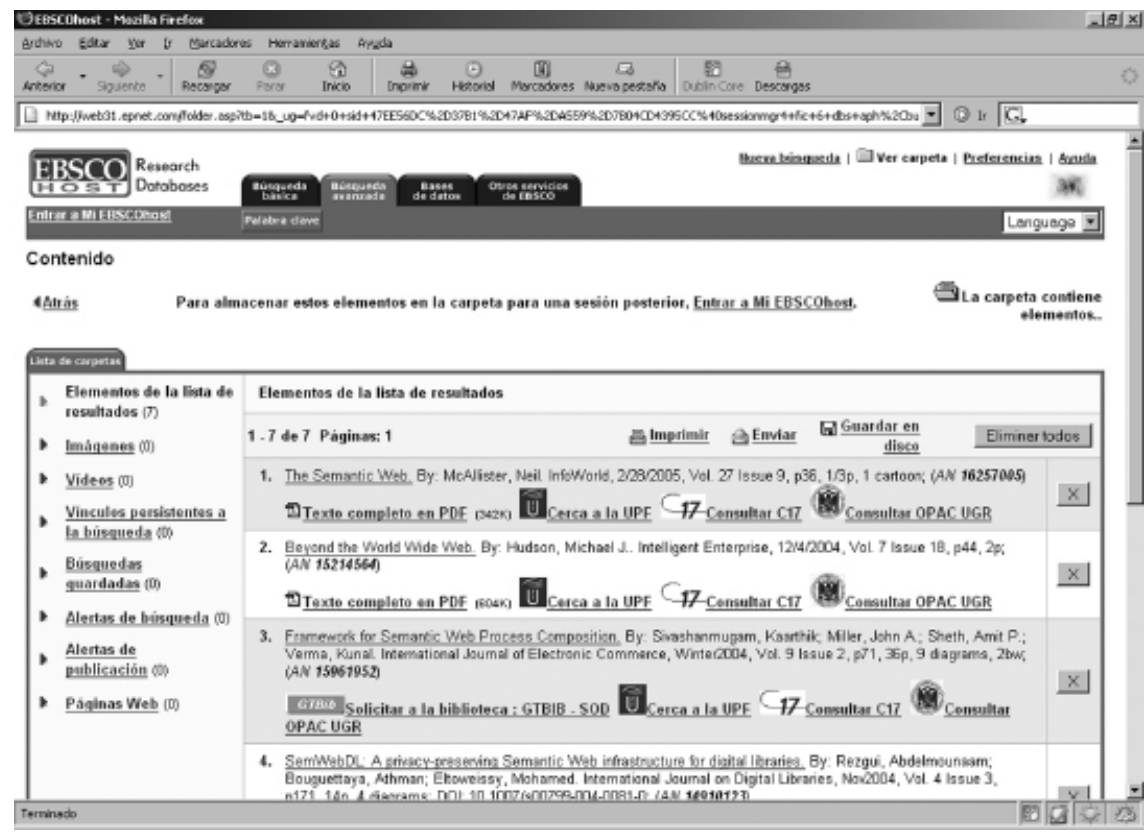

Figura 11. Mi EBSCOhost. Sistema de gestión de registros recuperados que permite desde crear alertas hasta generar páginas web con contenidos de EBSCOhost

$\mathrm{MeSH}$, etc. siempre dependiendo de las posibilidades de cada una de ellas. Por último, el sistema faculta la opción de decidir qué campos de la base de datos se mostrarán al usuario, en qué orden e, incluso, bajo qué denominación.

-Visualización de resultados: permite definir la cantidad y características a mostrar de la respuesta del sistema ante la pregunta del usuario. Cuestiones como número de resultados por página, cantidad de información del registro, forma- to de salida, gestión de imágenes anejas, mensajes informativos...

-Enlazar: para gestionar los enlaces entre la plataforma $E B S$ COhost y, por ejemplo, diferentes opacs o bases de datos externas que contengan alguno de los recursos referenciados. Por defecto incluye un vínculo con EJS para, especificando nombre de usuario y contraseña, hacer llamadas a revistas contenidas dentro de las bases de datos pero almacenadas en este sistema. Igualmente se incluyen, 
por defecto, los enlaces desde referencias en bases de datos bibliográficas al texto completo en bases de datos con texto completo en $E B S$ COhost o en una determinada colección de revistas electrónicas en la página de editores miembros de CrossRef.

-Envío: que gestiona las diferentes opciones que se le ofrecen al usuario para exportar los registros recuperados y marcados. Se pueden guardar, imprimir o enviar a una dirección de correo electrónico. El administrador decide en esta pantalla el número máximo de registros que se permiten exportar así como su formato de salida (cita, resumen, cita y resumen, campos seleccionados por el usuario, etc.).

-Multilenguaje: con el fin de proporcionarle al usuario la posibilidad de alterar el idioma de la interfaz una vez iniciada la sesión de trabajo o, incluso, la traducción de algunas partes del registro recuperado.

- Creación de marcas: tiene como principal objetivo el mostrar, en determinadas partes de la interfaz, logotipos corporativos así como vínculos a determinadas páginas de la organización o la inclusión del nombre de la misma.

Authentication: sirve para gestionar el acceso de los usuarios a determinadas partes del sistema EBSCOhost. El control se puede realizar por medio del clásico nombre/contraseña (permitiendo así aglutinar a diferentes usuarios dentro de un grupo determinado con el fin de asignarles los mismos privilegios, mismo tipo de interfaz, consulta a las mismas bases de datos, etc.) o empleando una ip dada o un conjunto determinado por medio de un rango, o según la página de referencia ("referring URL"). También se realiza desde aquí la gestión de cookies, la asignación de identificadores o la administración de ficheros de patrones, es de-

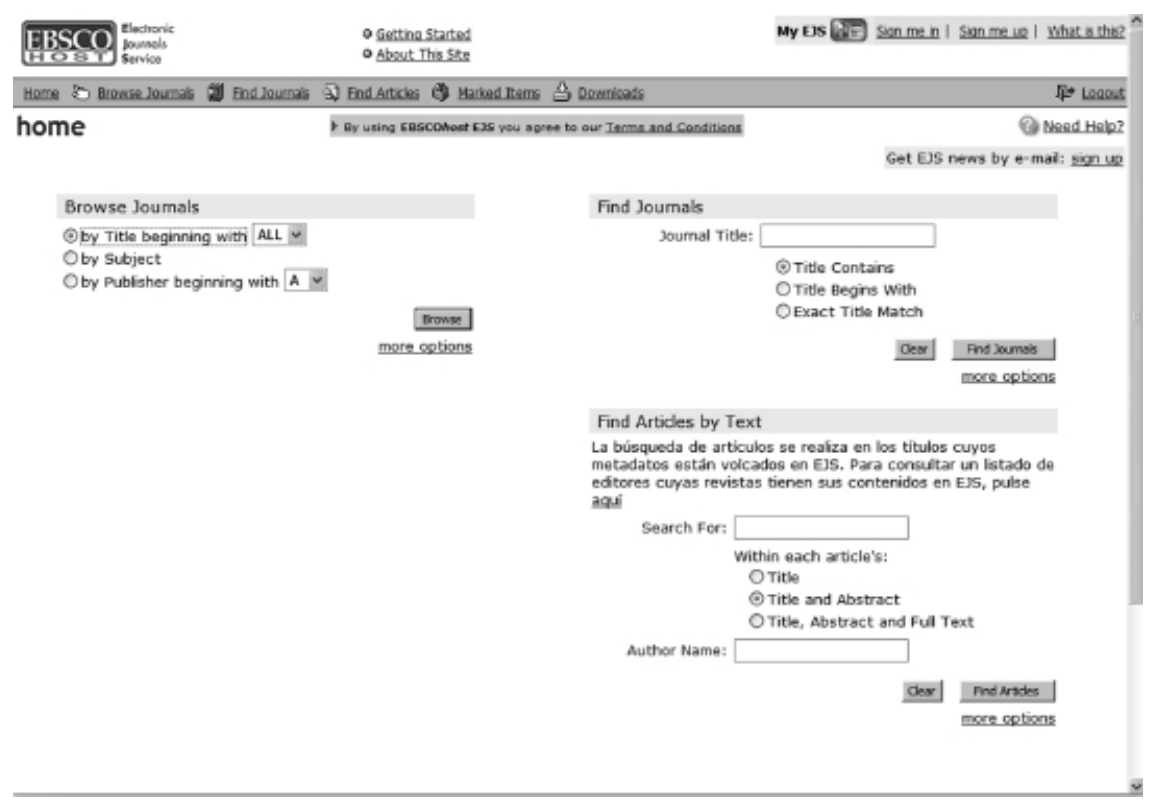

Figura 12. EJS provee tres formas de búsqueda: navegación por títulos/materias/editores de revistas, consulta por títulos de revistas, y búsqueda de artículos por título/resumen/texto completo

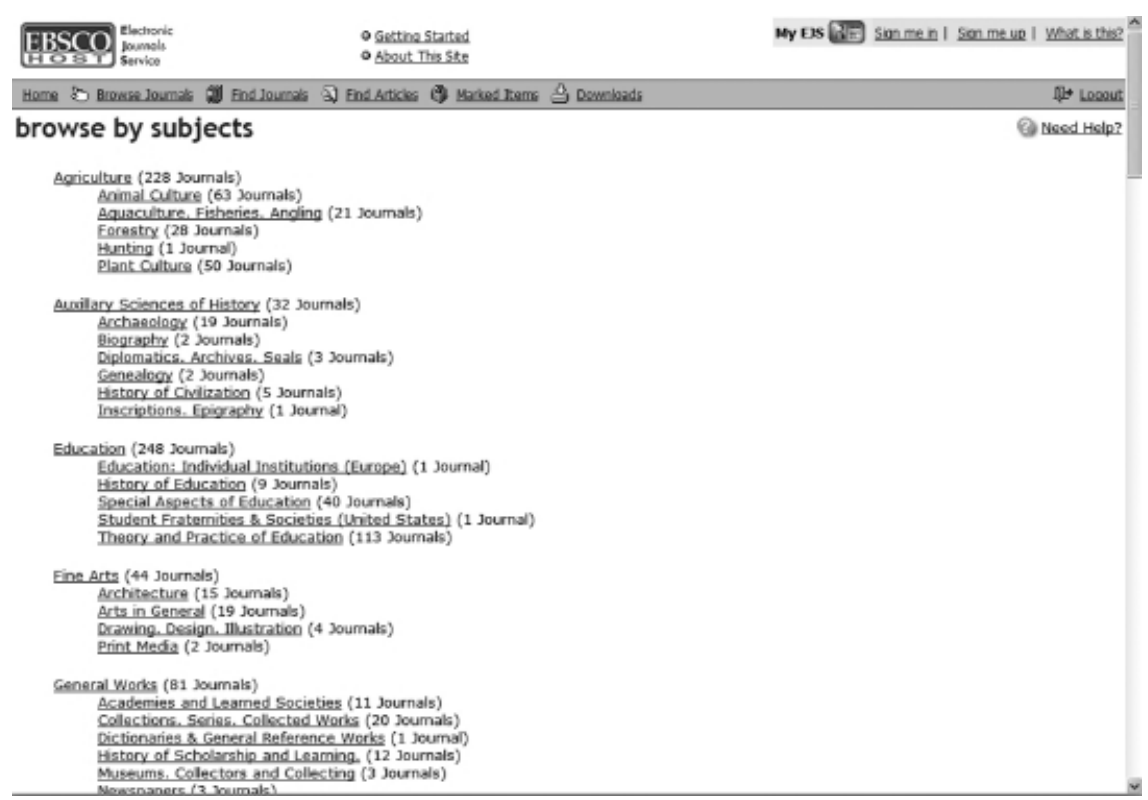

Figura 13. Desde una clasificación temática se accede a los títulos de las revistas relacionadas con estas materias

cir, las contraseñas no suministradas directamente por el sistema.

Local collections: que se emplea para añadir bases de datos a cada una de las colecciones que se decidan formar en el centro. Cada colección tendrá un identificador propio, una breve descripción y una configuración de títulos. La colección servirá para determinar a qué revistas debe limitarse cada enlace configurado por el administrador (por ejemplo, para limitar a la colección de títulos de la biblio- teca el enlace al opac, o los enlaces al texto de los artículos en una determinada colección de revistas electrónicas)

Reports \& Statistics: para controlar en todo momento el uso que se está haciendo del servicio. Genera informes en función de sesiones, direcciones ip, enlaces, informes según la norma Counter, etc.

Database title list: suministra una lista con los títulos a los que está suscrito el centro con la finalidad de poder integrarla dentro del 
catálogo de la biblioteca, la página web, etc. El formato de salida puede ser marc21, html o texto plano tabulado.

\section{EJS}

Este servicio permite el acceso a las publicaciones electrónicas suscritas por medio de Ebsco que se encuentran disponibles en el servidor de EJS (los llamados títulos residentes), así como a los sumarios y resúmenes disponibles en $E J S$ para las publicaciones no suscritas. En algunas ocasiones se da

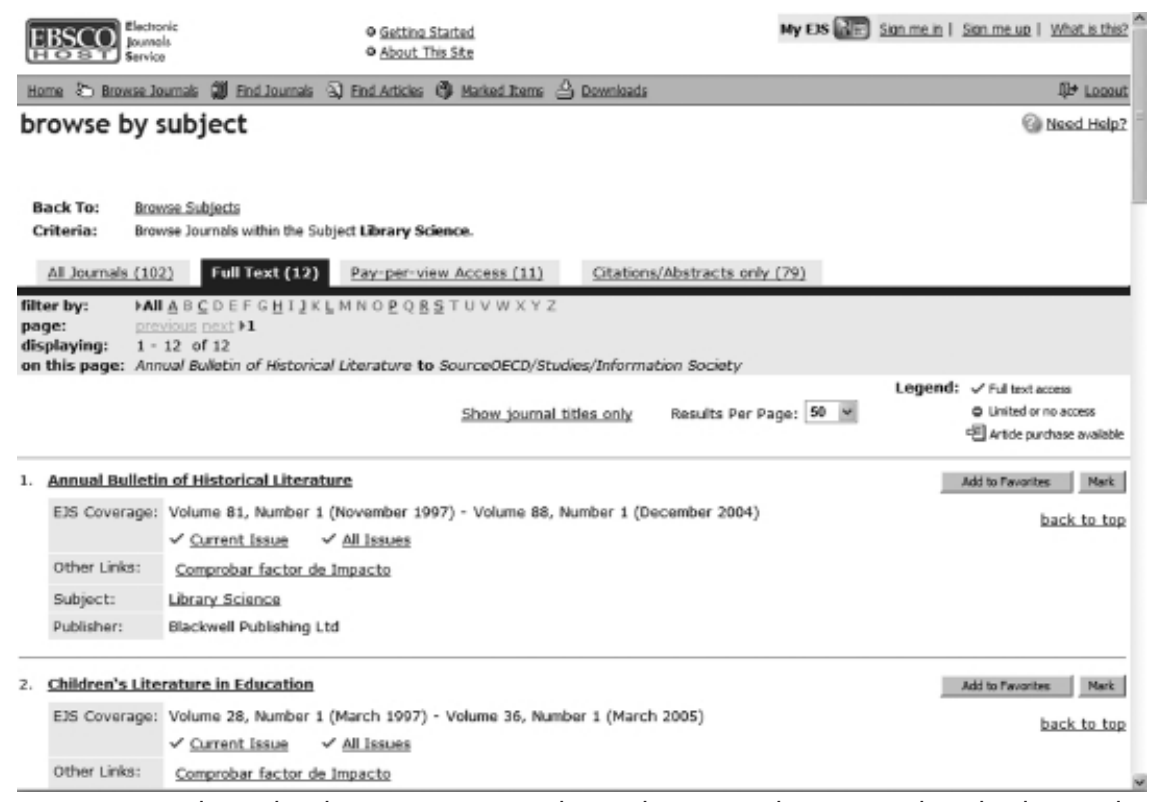

Figura 14. De los tífulos de revistas encontradas se da acceso al texto completo de algunos (los que estén suscritos con Ebscol, y el resumen o cita de otros, además de la opción de revisar los que se han adquirido mediante pay-per-view

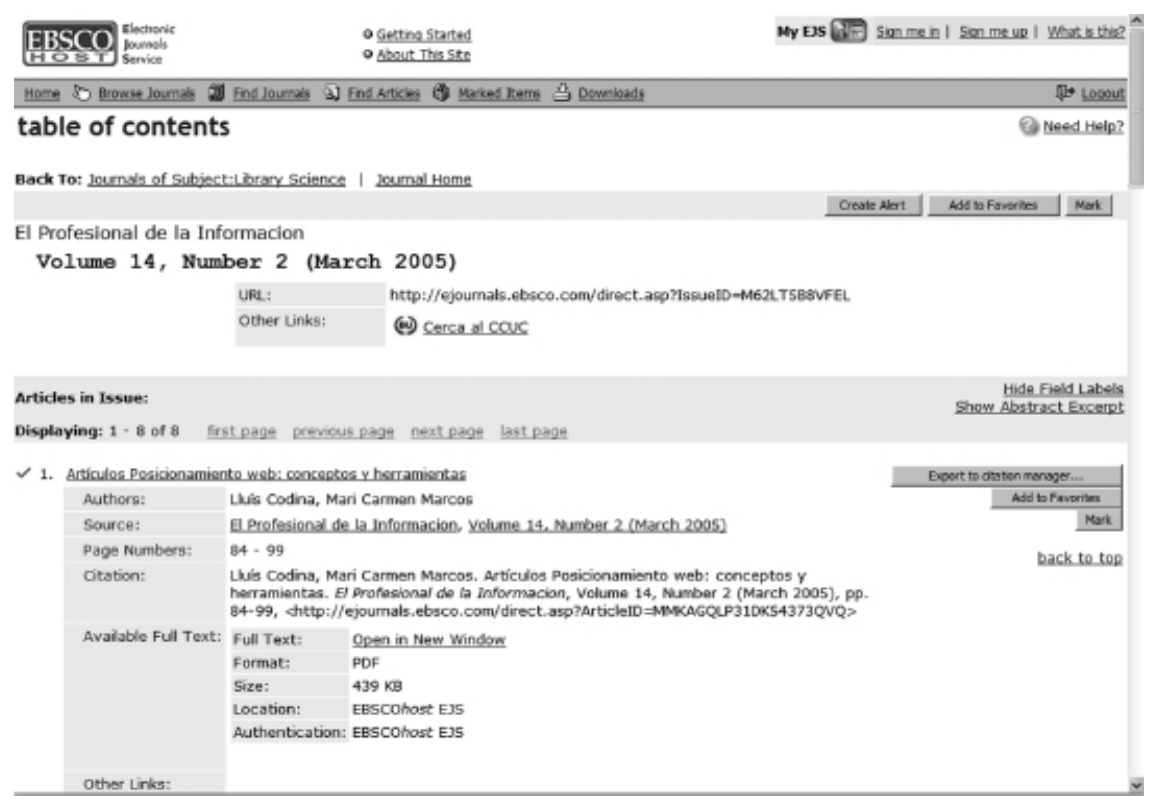

Figura 15. Sumario de un número de revista, con posibilidad de acceder al texto completo de los artículos
Los contenidos de los que dispone EJS pueden buscarse utilizando tres formas de acceso (figura 12):

\section{Browse Journals}

La búsqueda en este apartado puede hacerse por título de revista, nombre del editor o por materias (figura 13). El listado de revistas obtenido contiene alguna información sobre cada una: título, cobertura disponible en EJS, posibilidad de acceder al último número o a todos los números, un enlace al factor de impacto, la materia bajo la que está clasificada la revista, el nombre del editor; además de la posibilidad de añadirla a la lista de favoritos o de dejarla marcada (figura 14).

\section{Find Journals}

El sistema dispone de una opción de búsqueda básica desde la que introducir una consulta por título y una opción avanzada con más campos de búsqueda y posibilidad de combinaciones booleanas. El resultado de la búsqueda lleva al listado descrito anteriormente (figura 14).

\section{Find Articles by text}

Tanto desde la opción de browsing como desde la de find se obtienen por tanto las revistas sobre las que se ha hecho la consulta, y por navegación se llega también hasta un número concreto de una revista, su tabla de contenidos y la posibilidad de obtener el texto completo de un artículo. En cambio, si desde un primer momento se desea hacer una búsqueda directamente sobre los artículos, existe esta opción de "find articles" que, al igual que en la búsqueda de revistas, cuenta con una opción básica y otra avanzada. La búsqueda que se ofrece por defecto (figura 12) permite realizar la consulta en los títulos, en los títulos y los resúmenes y en los títulos, resúmenes y texto completo, o bien realizar una 
consulta por el nombre del autor. El resultado lo vemos en la figura 16 , donde se muestra la ficha del artículo recuperado y la posibilidad de acceder al texto completo (figura 17).

\section{My EJS}

Mediante esta opción cada usuario puede crear un perfil propio donde dispondrá de una forma permanente de la información que haya ido recopilando en $E J S$ en forma de:

- Lista de favoritos: recoge el título de las publicaciones elegidas, el número de la revista o el título de artículo, según el grado de detalle que se desee.

—Lista de alertas de publicación creadas por el usuario. El sistema avisa al usuario por correo electrónico cada vez que se añadan a EJS contenidos de una publicación determinada. Para solicitar el servicio de alerta basta con darse de alta (figura 18) rellenando un breve cuestionario.

-Búsquedas guardadas (SDI Saved searches): las búsquedas se pueden guardar en MyEJS para que el sistema alerte al usuario cada vez que se produzcan nuevos resultados coincidentes con los criterios de búsqueda.

-Recopilación de los artículos adquiridos mediante el sistema

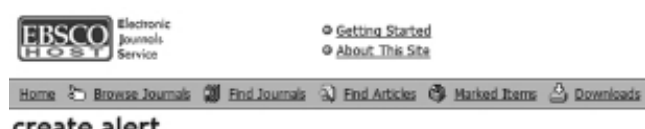

create alert

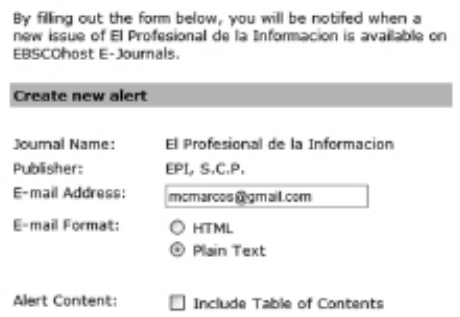

Cestentat Concel

Figura 18. El usuario de EJS puede indicar las alertas que desea recibir en su correo-e. De esta forma, será avisado cuando se introduce un nuevo número de una revista de su interés

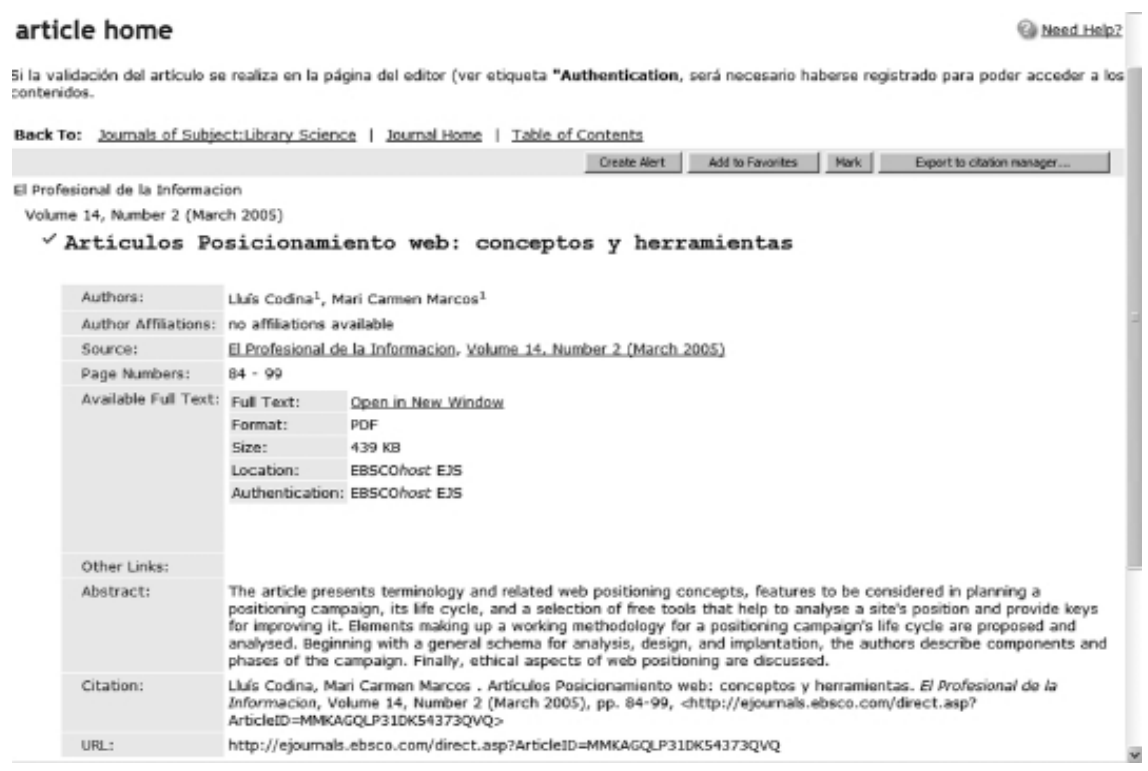

Figura 16. Registro de un artículo concreto con los datos de publicación, el resumen y los descriptores

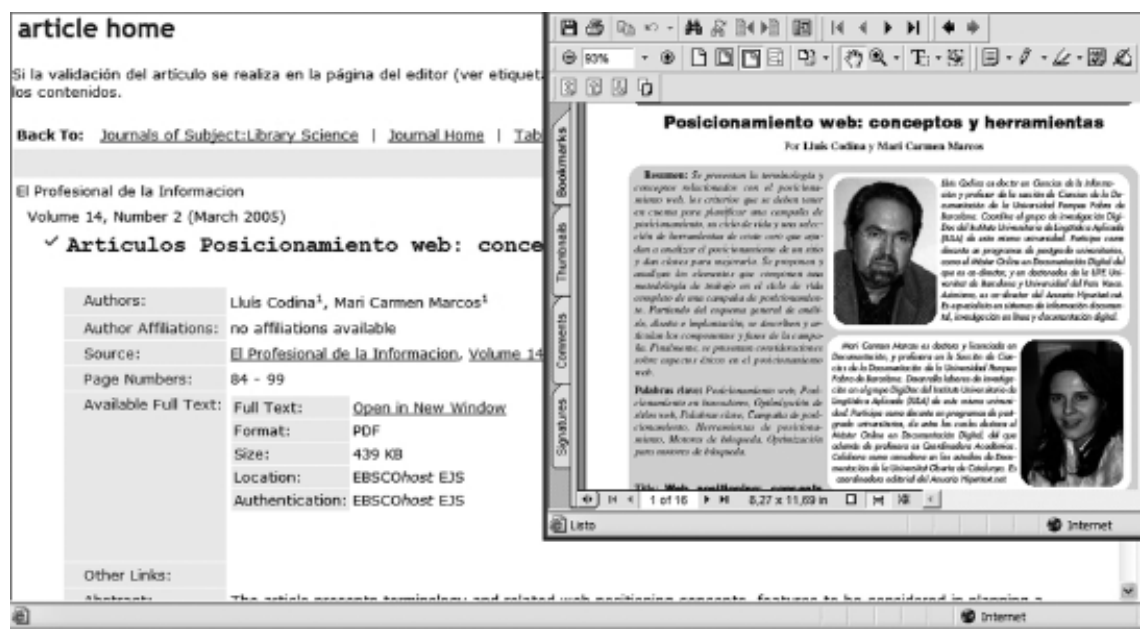

Figura 17. Texto completo de un artículo

pay-per-view. Un enlace permite acceder al texto completo de los artículos.

\section{Plataforma administrativa}

Este módulo permite la gestión de diversos aspectos:

\section{Gestión de acceso (access management)}

Permite crear perfiles de usuarios y asignarles métodos de validación de acceso (dirección IP, claves de usuario, página de referencia...), asignar grupos de revistas a usuarios, etc.

\section{Exclusión de contenidos (content exclusion)}

Permite al administrador excluir el acceso a aquellas pu- blicaciones que considere convenientes, ya sea para una parte o para la totalidad de los perfiles de usuario creados en la cuenta. Por ejemplo, el administrador puede decidir no mostrar al usuario aquellas revistas para las que no se haya completado el registro de acceso.

\section{Gestión de enlaces (linking management)}

Permite la descarga de un fichero con las URLs de las publicaciones electrónicas suscritas vía EBSCO y disponibles en EJS; de esta manera se garantiza una estabilidad que será independiente de los cambios que puedan sufrir las URLs de los respectivos editores. Los ficheros pueden descargarse 
de manera que se puedan recuperar en una hoja de cálculo MS Excel y determinar qué información adicional se quiere incluir. Las URLs se pueden obtener de acuerdo a la norma OpenURL.

\section{Enlaces (CustomLinks)}

Herramienta para crear enlaces dinámicos a recursos externos como opac web, servidores de resolución de enlaces OpenURL, formularios de obtención de documentos, buscadores en Internet, etc, y determinar las condiciones según las que se mostrará cada enlace.

\section{Seguimiento de registro (registration tracker)}

Permite al administrador completar una doble tarea:

-Acceder, organizar y llevar un registro completo de los diferentes pasos necesarios para la activación de una revista en la página de la editorial cuando este requisito sea necesario.

- Comunicar a los usuarios en la página de resultados de EJS todas aquellas incidencias que desee destacar, por ejemplo las claves que necesita introducir en la página de un portal determinado para poder acceder al texto completo.

\section{Alertas de administrador} (admin alerts)

Permite la creación de alertas que informarán puntualmente al administrador de los cambios en la cuenta de EJS de la institución: por ejemplo, el sistema avisará al administrador cuando haya una modificación del listado de suscripciones como consecuencia de un cambio en la política del editor en cuanto al acceso a la versión electrónica.

\section{Listado de revistas (jour- nal lists)}

El administrador puede descargar del servidor de EBSCO un fichero con la totalidad de las publicaciones disponibles en EJS o bien

\section{IweTeI}

Es un foro electrónico de debate, puesto en marcha por EPI - El profesional de la información, sobre información, documentación, biblioteconomía y sus tecnologías.

En la actualidad cuenta con más de 5.000 suscriptores.

Para suscribirse a IweTel hay que enviar a la dirección:

listserv@listserv.rediris.es

un mensaje en cuyo cuerpo figure:

subscribe iwetel Nombre Apellido

Se puede participar en IweTel remitiendo los mensajes a:

iwetel@listserv.rediris.es

Más información en:

http://www.rediris.es/list/info/iwetel.html

sólo de sus suscripciones en distintos formatos. Los ficheros incluyen información variada como el título de la publicación, el ISSN de la versión impresa y de la versión electrónica, el editor, la validación del acceso por EJS, si la revista dispone de resúmenes y sumarios en $E J S$, si se encuentra suscrita por la institución, la disponibilidad en el sistema de compra de artículos pay-per-view y la URL de la publicación en EJS. De igual modo, en el fichero obtenido se pueden modificar las notas de registro y acceso remoto para cada revista, de manera que al cargar el fichero de nuevo en EJS se reflejen los cambios en el administrador (registration tracker) y el usuario (notas de acceso)

\section{Preferencias (feature prefe- rences)}

El administrador puede determinar las preferencias del acceso a cada uno de los perfiles de usuarios creados: página de inicio y de salida del sistema, buscador predeterminado (de artículo o de revista), activar o desactivar pay-per-view y otras características.

\section{Personalización (branding)}

El sistema ofrece una serie de plantillas y la posibilidad de crear nuevas plantillas con el fin de per- sonalizar la interfaz de cada perfil de acceso creado por el administrador. Esto se logra mediante la utilización de logos institucionales, colores o imágenes de fondo, mensajes personalizados, etc.

\section{Informes estadísticos de uso (usage reports)}

EJS ofrece tres tipos de informes:

- uso general del sistema: incluye el número de conexiones, el número de ocasiones en que han sido consultados los títulos, los sumarios, los resúmenes y los textos completos, y el tipo de estrategia de búsqueda seguido por los usuarios

-uso por título de revista: incluye la actividad según la revista y pueden obtenerse estadísticas de los títulos suscritos o incluir los títulos no suscritos para analizar los que han tenido actividad a nivel de sumario o resumen

—actividad según artículos: incluye los datos de cada artículo descargado de EJS.

\section{Jose A. Senso, Universidad de Granada jsenso@ugr.es}

Mari Carmen Marcos, Universitat Pompeu Fabra mcarmen.marcos@upf.edu 


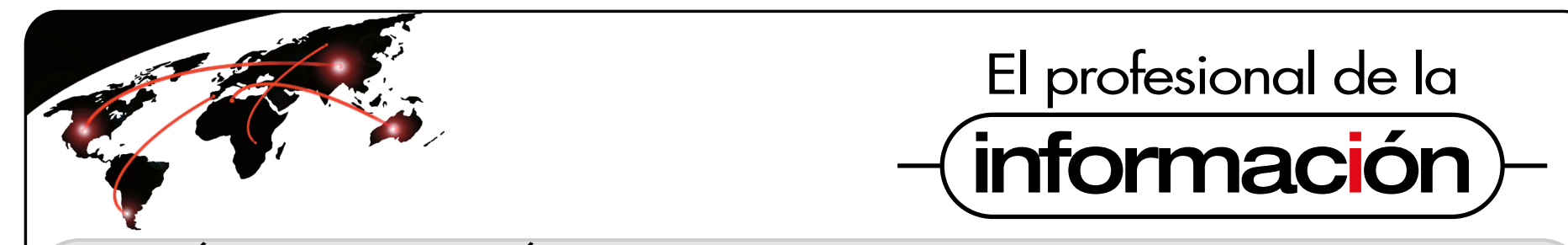

\section{BOLETÍN DE SUSCRIPCIÓN}

Deseo recibir todos los números de la revista EPI a partir del mes de enero del año

Suscripción: Institucional Personal

Nombre: Institución:

(Los suscriptores individuales no han de escribir ningún nombre de institución, sólo indicar la direcci

Departamento:

Dirección:

Código postal:

Teléfono:

al:
Ciudad:

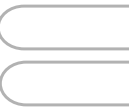

NIF institucional:

Método de pago:

Tarjeta de crédito: $\bigcirc$ VISA Master Card American Express

Titular de la tarjeta:

Número de tarjeta:

Caducidad (mm/aaaa):

Cheque nominativo en euros a nombre de El profesional de la información

Transferencia bancaria a la cuenta de La Caixa 21000818930200745544 Enviar, fotocopiado o escaneado, el resguardo de la transferencia. Las transferencias desde fuera de España deben hacerse a: IBAN ES95 21000818930200745544

BIC/Código Swift CAIXESBBXXX

Giro postal al apartado de correos 32.280 de Barcelona Enviar, fotocopiado o escaneado, el resguardo del giro.
Los precios para el año 2005 son los mismos de 2004

Suscripción anual Institucional:

129 euros + 4\% IVA Individual:

75 euros $+4 \%$ IVA

Número suelto: 22 euros

A los pagos realizados desde países distintos de España se les aplicará el IVA o VAT local. A todas las suscripciones de fuera de Europa se les aplicará un recargo de 60 euros en concepto de correo aéreo.

La suscripción a la revista se realiza por años naturales completos, es decir, desde el mes de enero del año que usted desee que comience su nueva suscripción.

Domiciliación en cuenta bancaria

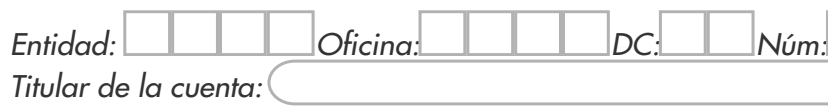

Boletín para comenzar o renovar online la suscripción: http://www.elprofesionaldelainformacion.com/suscripciones.html

Todos los profesionales que lo deseen pueden remitir a la redacción de la revista El profesional de la información sus colaboraciones en forma de:

- Notas breves

- Trabajos más amplios sobre temas de fondo para la sección "Artículos".

El texto ha de enviarse en formato electrónico. Aparte, los materiales gráficos, en papel o ficheros gif, ipeg o tiff con unos anchos de entre 12 y 5,7 cm. y una resolución de 300 ppp.

El tamaño ideal de un estudio para la sección "Artículos" es de 4.000 palabras. En casos excepcionales pueden publicarse artículos de mayor extensión. Los trabajos de esta sección son aprobados según el sistema tradicional "peer review": al menos dos expertos en el tema, del Consejo Asesor de la revista y/o externos, deben dar el visto bueno antes de su publicación.

Los textos deben enviarse sin formatos especiales (títulos, secciones, subsecciones, pies de página, sangrías, tabulaciones, colores, etc.).

Los trabajos para la sección "Artículos" deben incluir: a) título en castellano, b) resumen en castellano de 100-150 palabras, c) 5-10 palabras clave en castellano, d) título en inglés, e) resumen en inglés de 100-150 palabras, f) 5-10 palabras clave en inglés, g) texto completo en castellano y h) nombre de los autores, lugar de trabajo y dirección de correo electrónico. Han de ser inéditos.

Se valorará especialmente que los trabajos sean concisos y precisos. Se ruega a los autores que eviten una excesiva retórica.

Las citas bibliográficas en el texto se realizarán de la forma: (Apellido, año). Las referencias bibliográficas, que se limitarán a las obras citadas en el texto, han de prepararse de acuerdo con

\section{Información para los autores}

el siguiente esquema:

Artículos de una publicación periódica:

Apellido, Nombre; Apellido2, Nombre2. "Título del artículo". En: Título de la publicación periódica, año, mes, v. [volumen], n. [número del ejemplar], pp. [págs. comienzo-final].

Ponencia presentada en un congreso:

Apellido, Nombre; Apellido2, Nombre2. "Título de ponencia". En: nombre del congreso, año, pp. [págs. comienzo-final].

Capítulo de una monografía:

Apellido, Nombre; Apellido2, Nombre2. Título del capítulo. En: Apellido, Nombre; Apellido2, Nombre2. Título de la monografía. Lugar de publicación: editor, fecha. ISBN [número].

Monografías:

Apellido, Nombre; Apellido2, Nombre2. Título del trabajo. Lugar de publicación: Editor, fecha. ISBN [número]

Recurso en línea:

Apellido, Nombre; Apellido2, Nombre2. Título del recurso. Consultado en: día-mes-año.

dirección

Las contribuciones se pueden enviar a la redacción de la revista o a cualquiera de los miembros del consejo de redacción.

El hecho de que un trabajo sea publicado en EPI no implica que la redacción se adhiera a las opiniones expresadas en él.

\section{Redacción EPI:}

Apartado 32.280

08080 Barcelona.

epi@elprofesionaldelainformacion.com

La redacción se reserva el derecho de adaptar los textos al estilo gramatical y literario de la revista. 